\title{
Energy Metabolism Process
}

National Cancer Institute

\section{Source}

National Cancer Institute. Energy Metabolism Process. NCI Thesaurus. Code C16547.

Any subcellular or molecular event, process, or condition concerned with storing and generating metabolic energy. 